Departments of Emergency Medicine, Environmental and Occupational Health Sciences, and Global Health, and Center for Health and the Global Environment, Schools of Medicine and Public Health, University of Washington, Seattle, WA USA

2 Caribbean Public Health Agency (CARPHA), Port of Spain, Trinidad and Tobago

3 Department of Geography and Environmental Studies, University of Haifa, Haifa, Israel

4 Inter-American Institute for Global Change Research (IAI), Montevideo, Department of Montevideo, Uruguay

5 Departments of Global Health and Medicine, Schools of Medicine and Public Health, University of Washington, Seattle, WA USA

6 Centre on Climate Change \& Planetary Health and Centre for Mathematical Modelling of Infectious Diseases, London School of Hygiene and Tropical Medicine, London, UK

7 Barcelona Institute for Global Health (ISGlobal), Spain

Correspondence to: I Hess ijhess@uw.edu; R Lowe rachel.lowe@lshtm.ac.uk Cite this as: BMJ 2020;371:m3081 http://dx.doi.org/10.1136/bmi.m3081 Published: 26 October 2020
CLIMATE CHANGE AND COMMUNICABLE DISEASES

\section{Strengthening the global response to climate change and infectious disease threats}

\section{Climate change is emerging as an important driver of disease incidence, and a wait and see approach invites unnecessary risk, write Jeremy Hess and colleagues. Governments, funders, researchers, and practitioners must act now}

\section{Jeremy Hess, ${ }^{1}$ Laura-Lee G Boodram, ${ }^{2}$ Shlomit Paz, ${ }^{3}$ Anna M Stewart Ibarra, ${ }^{4}$ Judith N Wasserheit, Rachel Lowe 6,7}

Global health leaders have identified climate change as the greatest health challenge of the 21st century. ${ }^{1}$ Impacts on infectious disease are a particular concern: there is growing evidence that some of the greatest health impacts of climate change are, and will continue to be, on the emergence, re-emergence, and spread of infectious diseases. ${ }^{2}$ For at least two decades, global assessments have highlighted the need to reduce greenhouse gas emissions ${ }^{34}$ and to invest more substantially in climate and health, including surveillance, preparedness, and response. ${ }^{5-7}$

The global health response has largely been characterized by scepticism and watchful inaction. The world's largest global health funders, including the US National Institutes of Health (NIH) ${ }^{8}$ and the Bill and Melinda Gates Foundation (BMGF), still lack specific climate and health programming, let alone programming focused on climate change and infectious diseases. Climate change remains a vanishingly small element of the portfolio of funders like the European Commission and the Wellcome Trust that have stepped into the breach. Funding for training, research, and practice related to climate change and infectious disease has been limited accordingly.

This is partly because the evidence is difficult to parse. ${ }^{9}$ The rationale for an association between climate change and infectious disease is clear, and mosquito-borne pathogens, particularly malaria and dengue, are of particular concern ${ }^{10}{ }^{11}$ given established climate sensitivities of vector populations. ${ }^{1213}$ But evidence of major impacts of climate change on communicable disease has been somewhat limited. The relative importance of climate variability and change has been difficult to evaluate among drivers of disease incidence such as globalization, urbanization, migration, land use changes, poverty, vector-pathogen characteristics, and control measures. ${ }^{14}$ In recent years, the world has seen substantial declines in many prevalent infectious diseases, including malaria, yellow fever, lymphatic filariasis, schistosomiasis, onchocerciasis,
Chagas disease, and African trypanosomiasis, ${ }^{15}$ indicating that other drivers have obscured any climate change contribution to disease incidence.

\section{Gaps in the evidence base}

Ruling out climate change as a key driver of infectious disease risk is premature, however, for several reasons. First, our evidentiary database is incomplete. Some areas that have experienced substantial shifts in climate (such as areas of Africa and the Middle East) are under-represented in the evidence base, which limits conclusions about climatic influences in certain regions. ${ }^{16}$ Second, there is limited research on the role of interannual climate variability, which is important for many infectious diseases with a marked seasonal component. Third, insufficient attention has been paid to the effects of increasingly frequent and severe extreme weather events, which have a known association with infectious disease outbreaks. ${ }^{1718}$ A precautionary approach would argue for more research, at a minimum, to settle any remaining doubts.

In addition, interactions between climate change and other infectious disease drivers seem to be accelerating. Over two thirds of human infectious diseases are zoonotic, causing widespread morbidity and mortality. ${ }^{19}$ Zoonotic disease spillover is determined by interactions between humans and natural systems. ${ }^{20}$ Increasingly widespread disruption of landscapes and biodiversity, through deforestation and agricultural development, changes socio-ecological systems and forces humans, vectors, livestock, and pathogens into increasingly closer contact. ${ }^{21}$ For example, land use and land cover changes, in parallel with temperature increase, may contribute to the spread of leishmaniasis by moderating vector activity. ${ }^{22} 23$ This, combined with unplanned and precarious urbanization, increasing global connectivity via international travel and trade, and climate variability, can allow invasive vectors and novel pathogens to spread widely, with the potential for transcontinental pandemics with devastating public health, social, and economic consequences. $^{24}$ 


\section{thebmj Visual summary}

Funding for training, research, and practice related to climate change and infectious disease has been limited, and the global response has largely been characterized by skepticism and watchful inaction. This graphic introduces six strategies for intervening in the complex network of connections around climate change and infectious disease
Climate change and infectious disease

Now is the time for bold transdisciplinary action

\begin{tabular}{|c|c|c|c|c|}
\hline \multirow{2}{*}{$\begin{array}{l}\text { Health sector } \\
\text { emmisions mitigation }\end{array}$} & \multicolumn{4}{|c|}{ Increased funding for climate and health } \\
\hline & \multirow{2}{*}{\multicolumn{4}{|c|}{$\begin{array}{l}\text { Nations must invest in appropriate strategies to further } \\
\text { elucidate linkages and address climate related health risks }\end{array}$}} \\
\hline \multirow{2}{*}{$\begin{array}{l}\text { The health sector is responsible } \\
\text { for over } 4 \% \text { of global emissions, } \\
\text { more than aviation or shipping. } \\
\text { Reducing emissions should be } \\
\text { a fundamental priority }\end{array}$} & & & & \\
\hline & $\begin{array}{l}\text { Integrated } \\
\text { surveillance } \\
\text { and control }\end{array}$ & $\begin{array}{l}\text { Community } \\
\text { education } \\
\text { and social } \\
\text { mobilization }\end{array}$ & $\begin{array}{l}\text { Interventions } \\
\text { in displaced } \\
\text { populations }\end{array}$ & $\begin{array}{c}\text { Novel } \\
\text { diagnostics }\end{array}$ \\
\hline
\end{tabular}

zation

\section{Recognize and frame the problem with a transdisciplinary lens \\ The health of humans, plants, and animals is inextricably linked. For this reason, multiple sectors and disciplines must come together to improve health and wellbeing, and new systems of collaboration integrated into ongoing health assessments}

\section{More international travel and trade

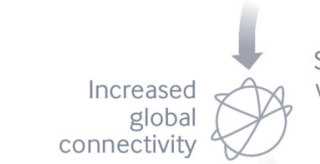 \\ Decision support analytics \\ Predictive modeling and early warning systems that integrate seasonal climate forecasts have the potential to assist decision makers in understanding where infections will emerge or spread, or when future epidemics might occur}

Enhanced use of environmental information

Integrating Earth observations and local environmental observations into burden of disease estimates and disease surveillance activities could allow for the early detection of anomalies and facilitate preemptive action

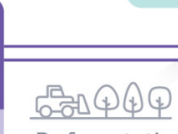

\section{Deforestation and} agricultural development
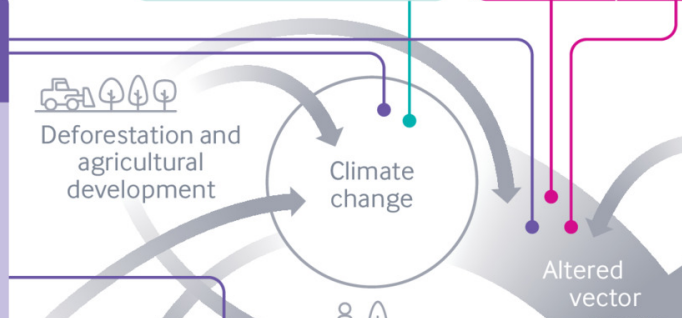

\begin{tabular}{l|l|l|l|} 
KNOWLEDGE & $\begin{array}{l}\text { 1. Location, location } \\
\text { Some areas that have experienced } \\
\text { significant shifts in the climate, including } \\
\text { parts of Africa and the Middle East, are } \\
\text { underrepresented in the evidence base, } \\
\text { which limits conclusions about climatic } \\
\text { influences in certain regions }\end{array}$ & $\begin{array}{l}\text { 2. Annual trends } \\
\text { There is limited research } \\
\text { on the role of interannual } \\
\text { climate variability, which is } \\
\text { important for many infectious } \\
\text { diseases with a marked } \\
\text { seasonal component }\end{array}$ & $\begin{array}{l}\text { 3. Extreme events } \\
\text { Insufficient attention has been } \\
\text { aid to the impacts of increasingly } \\
\text { frequent and severe extreme weather } \\
\text { events, which can influence the timing } \\
\text { and intensity of disease outbreaks and } \\
\text { hinder response efforts }\end{array}$
\end{tabular}

\section{thebmi Read the full http://bit.ly/BMJcccd}

\section{Tipping towards action}

The detection and attribution of climate change effects on infectious diseases is challenging, ${ }^{25}$ but substantial progress has been made. Climate change is emerging as an important driver in several cases. Dengue incidence, for example, has risen sharply over recent decades, and prior consensus has held that climate change is just one of many contributing factors. ${ }^{26}$ But recent analyses indicate that climate change has had a more decisive role $e^{27}$ and that climate change could have similar effects on other mosquito-borne diseases in some regions. ${ }^{28}$ Other analyses have implicated climate change in the increasing incidence of diseases like Lyme and tick-borne 
encephalitis. ${ }^{2930}$ Notably, this evidence has arisen from groups based in regions with more access to climate change and health research funds.

Other signs of increasing effects of climate change on infectious disease are emerging. For example, malaria incidence is increasing in the highlands of Colombia and Ethiopia, ${ }^{31}$ Lyme disease is expanding its range northward as the climate warms, ${ }^{29}{ }^{32}$ and arboviral diseases are extending from the tropics into temperate regions globally. ${ }^{33}$ In Europe, climate change has facilitated the spread and establishment of West Nile virus in new regions. ${ }^{34}$ There are also signs that the autochthonous spread of some infectious diseases may be facilitated by climatic changes increasing ecological suitability (the availability of niches suitable for vectors and pathogens) ${ }^{35}$ and vectorial capacity (the ability of the vector to transmit the disease) in multiple settings. ${ }^{36} 37$ Emerging evidence reinforces concern for the future due to projected warming, urbanization, and global connectivity, ${ }^{38}$ including large parts of Europe and Eurasia. 39

The steady acceleration of climate change emphasizes the need for a more active posture to take advantage of response options while they are still available. Climate change is accelerating and ecosystems are nearing dangerous tipping points, ${ }^{40-42}$ promoting infectious disease transmission through multiple pathways. One common pathway is increased transmission of zoonotic diseases between wildlife and domesticated animals. ${ }^{43}$ Other pathways involve ecosystem changes. In wetland ecosystems, for example, heat and drought conditions may lead to water bodies shrinking and organic matter becoming more concentrated (eutrophication). Such conditions favour Culex pipiens, the main vector of West Nile virus. ${ }^{44}$ The acceleration of these trends has the potential to constrain the range of response options we have at our disposal. 45

Finally, climate change is likely to worsen infectious disease impacts by increasing sequelae and complicating control efforts. Climate change is expected to worsen food security and nutritional status, ${ }^{46}$ limiting host ability to recover from infectious diseases and worsening sequelae. Migration, in response to increasingly scarce resources-such as water and arable land-and to sea levels rising, 47 is also likely to create fertile conditions for infectious disease outbreaks that confound conventional control strategies.

\section{Increasing resilience in global infectious disease practice}

A wait and see approach to climate change and health is short sighted and invites unnecessary risk. Based on the weight of the evidence and established calls for specific actions, we recommend key, "low regrets" strategies to reduce health risks associated with climate change by improving the ability to anticipate and engage infectious disease risks effectively.

\section{Reduce carbon footprint}

Globally, the health sector emits $4 \%$ of the world's greenhouse gases, more than aviation or shipping, ${ }^{48}$ sectors that have been scrutinized for their climate change contributions. To limit warming to $1.5^{\circ} \mathrm{C}$ without carbon removal from the atmosphere, emissions from all sectors need to decline to zero by 2050,49 moving well beyond commitments made in the Paris Agreement. Health sector emissions are driven principally by domestic energy system intensity, the carbon intensity of the domestic economy, and demand for health services. ${ }^{48}$ Major reductions in the health sector are feasible and consistent not only with maintaining but also advancing population health. The UK National Health Service is working to reduce its greenhouse gas emissions by $80 \%$ from a 1990 baseline by 2050. Strong advocacy from the health sector to reduce carbon emissions is thus one of the more important levers for reducing its own carbon footprint, as is investment in energy efficiency in procurement and operations. ${ }^{50}{ }^{51}$ These investments are consistent with the sector's mission: Mitigation activities have well established benefits for health, 5253 including reduced pollution exposure and less obesity through healthier diets and more walking and cycling. Other efforts are needed, as well. The health sector has been slow to divest from fossil fuels and should lead by example. 35455 Climate change mitigation in healthcare systems must be adopted universally to achieve collectively endorsed mitigation targets, and help for poorer countries for greening their health sectors should be part of this commitment. A by-product of responses to the covid-19 pandemic has been reduced emissions of greenhouse gases and other harmful co-pollutants. ${ }^{56}$ While they hold the world's attention, health systems can work to leverage these temporary reductions through the mechanisms mentioned above and seize the opportunity to promote further greening during recovery efforts. ${ }^{57}$

\section{Increase funding for climate and health}

Nations should acknowledge and invest in strategies to further elucidate links and tackle climate related health risks. The discipline of climate and health has been systematically deprived of funding for training, research, and other activities, including development and testing of interventions. ${ }^{8}$ There is a conspicuous lack of investment in climate and health from major global health funders including the BMGF and the NIH. Although funders such as the Wellcome Trust have tentatively engaged climate and health programming, their investments have been relatively timid in ambition and limited in scope. The Belmont Forum has recently prioritized climate and health, but direct funding from health agencies is limited, and funds cannot be spent in the countries most affected despite their lack of contribution to the underlying problem and need for capacity. ${ }^{58}$

Recent years have seen some positive developments, including investments from the European Union and other international agencies in the Caribbean region for climate and health initiatives. This was spurred by regional advocacy and recognition of the high vulnerability of health systems in Caribbean small island developing states, particularly to climate related disasters. Nevertheless, investment is directed principally towards infectious disease diagnostics and therapeutics to tackle negative health outcomes. Investigating and tackling climate change health effects and greening global health practice are afterthoughts, despite the potential for climate change to undermine the global health gains of recent years.

\section{Frame the problem with a transdisciplinary lens}

Framing is important to characterizing problems and identifying response options. Several interdisciplinary and intersectoral concepts have been proposed to offer a more proactive and holistic framework for tackling global health threats, such as ecohealth, one health, planetary health, planetary epidemiology, and planetary wellbeing. 5960

These concepts share the notion that the health of humans, plants, and animals and the planet is inextricably linked. Other frameworks have identified the central importance of social determinants of health. ${ }^{6162}$ All of these frameworks reflect the fundamental importance of multiple sectors and disciplines coming together to improve health and wellbeing and the potential for working at cross-purposes when sectors do not work together. 
These concepts have been embraced but not fully realized, as noted elsewhere in this collection. Transdisciplinary teams can learn to design more robust surveillance systems, develop innovative methodologies (such as quantifying and communicating model uncertainty and performing forecast verification) and effective communication strategies for target audiences on international, national, and city levels. Such teams could also bring in climate scientists and meteorologists to satisfy the longstanding suggestion for a merged community of practice. 6364

A broader frame could also lead to coupled action: efforts to reduce infectious disease effects such as mosquito net distribution could be linked with efforts to electrify villages, facilitating climate change mitigation and reducing population susceptibility to multiple hazards at the same time.

\section{Incorporate environmental information into public health practice}

The global response to climate change and its effects needs better information to support decision making. The past decade has seen progress towards integrating climatic data into the surveillance of infectious diseases. The Global Framework for Climate Services provides guidance on how to bring climate information into the mainstream of health sector activities.

Because this has not been broadly adopted in public health practice, however, many shortfalls still exist, including the lack of harmonization in the collection of climate and health data needed to inform climate adaptive responses. Integrating Earth observations (from satellites, weather stations, or drones, for example) and local environmental observations (such as from citizen science initiatives) into burden of disease estimates and disease surveillance activities could allow for the early detection of anomalies and facilitate pre-emptive actions.

Recognising the utility of the Global Burden of Disease (GBD) study and leveraging experience from that effort, the global health community could come together to pursue a major synthesis in environmental and health data, for example an effort to link GBD data with data on ecosystem health and services. The Lancet's Countdown on Health and Climate Change gestures towards such an analysis, ${ }^{54}$ but there is potential for more substantial

interdisciplinary collaborations, including interactions with policy makers. Leaders from the health community, including those from the GBD study, have emphasised the importance of such expanded efforts. ${ }^{65}$

These initiatives will need to quantify and characterise exposure, vulnerability, and risk for populations and health systems, identify and track key effects on population health over time, and attempt to identify the climate change components of infectious disease systems, among other health risks resulting from the changing climate, to help inform adaptation, mitigation, and surveillance strategies. These efforts will need to be well crafted, because effective transdisciplinary approaches rely on early, strong partnerships among diverse scientific experts and stakeholders (including policy makers, the private sector, and civil society) to ensure that the outcomes are relevant in guiding and informing actions. Relevant examples of successful efforts include several assessments of national vulnerability and adaptation, national adaptation plans for health, assessments of city climate risk, and projects using available adaptation funding. The Middle East Consortium on Infectious Disease Surveillance, for example, highlights the potential for regional collaborations.

\section{Invest in decision support modeling tools and communication}

Established effective global health practices should be retained but need to be integrated with other strategies to support management decisions. Computational models can help disentangle and quantify the role of multiple infectious disease transmission risk factors, including climatic and environmental factors, human mobility, socioeconomic status, asymptomatic infections, and background immunity.

Predictive modeling has the potential to help decision makers understand where infections will emerge or spread or when future epidemics might occur. Outbreak predictions that use seasonal climate forecasts can prepare public health systems months in advance of a period of heightened risk of disease outbreaks, particularly in areas sensitive to large scale climate phenomena, such as the El Niño Southern Oscillation. ${ }^{1854}$

Combining novel data streams, including seasonal forecasts and local seroprevalence data, in early warning systems could improve predictions of the timing and magnitude of outbreaks of multiple diseases. ${ }^{65}$ Modeling approaches and processes for evaluating future climate change effects on infectious disease must be co-designed in partnerships involving public health climate practitioners and aligned with local priorities and capacities to identify the most appropriate spatial resolution and tackle cross scale problems. ${ }^{13}$

Supporting uptake of findings from these efforts is also important. A key component of effective model communication is the provision of user friendly interfaces to openly share and visualize results and to provide access to modeling architecture to allow for scrutiny and reproducibility. ${ }^{63}$ Educating policy makers and other stakeholders regarding modeling processes and interpretation of findings is also essential. ${ }^{564}$ Challenges related to interpreting modeling results have been apparent in the covid-19 response, with software engineers, decision makers, and the public calling for more transparent sharing of evidence used to inform vital decisions, and policy makers struggling to interpret seemingly disparate recommendations based on different model outputs. Looking forward, funders need to consider data science and software engineering as key components of any scientific tool kit and transdisciplinary epidemiological taskforce.

\section{Build human capacity in data management, integrated surveillance, and leadership}

Additional investment for incorporating climate considerations into global health practice, if and when it comes, should support training to maximize the effectiveness of programmatic investments. Although the discipline has continued to make halting progress, awareness remains low among the public health community of climate related epidemiological and assessment tools. ${ }^{35} \mathrm{We}$ recommend updated and expanded health professional educational programming. Sustained funding is essential for risk assessment, intervention development, programme evaluation, and implementation; for training the next generation of climate and health leaders to facilitate the requisite interdisciplinary collaborations; for maintaining longer term projects for sustained impact and learning about implementation strategies.

In addition, funders should prioritize support for surveillance that incorporates environmental information and skills training for interdisciplinary practice. ${ }^{66}$ For example, easy to implement, low cost actions might include integrating weather data collection with malaria surveillance..$^{52}$ A recent study in the Caribbean ${ }^{67}$ found that technical expertise in statistics, data science, and geographic information systems in the health sector needed to be strengthened 
to interpret basic climatic information and integrate this information into a health early warning system. At the same time, climate practitioners need a better understanding about the decision priorities and needs of the health sector to be able to provide relevant bespoke and useful climate indicators. An early warning system requires an integrated approach that cuts across research, health and climate operations, data and knowledge sharing platforms, outreach and education, and in country response activities. There are challenges to interdisciplinary design and work of this sort, including the need to develop shared language, perspective, and methods, ${ }^{64}$ and future funding should recognise these concerns. Such climate resilience actions should leverage and engage with other global health innovations that aim to reduce the burden of infectious diseases such as the development of rapid, accurate, low cost diagnostics; novel therapeutics and vaccines; innovative vector control and surveillance tools; and community education and social mobilization via social media.

\section{Call to action in global health practice}

Global health has been defined as "an area for study, research, and practice that places a priority on improving health and achieving equity in health for all people worldwide... [that] emphasises transnational health issues, determinants, and solutions; involves many disciplines within and beyond the health sciences and promotes inter-disciplinary collaboration; and is a synthesis of population-based prevention with individual-level clinical care."68

The global health community has many actors that pursue this common agenda, including multilateral organizations; funders, including governments and foundations; non-governmental organizations; researchers; and practitioners. Action on climate and health, called out as an increasingly urgent priority by the World Health Organization (WHO), the Intergovernmental Panel on Climate Change (IPCC), and 197 signatories to the Paris Agreement, is squarely in the domain of global health, including its primary funders, organizations, and partners. Yet the calls of these multilateral organizations and governments have, in most cases, been met with a tepid response by global health funders and practitioners.

The covid-19 pandemic has taught us the consequences of unheeded warnings, and similar effects, drawn out over a much longer timeframe, are increasingly likely as a result of years of inaction on climate and health. There is now increased attention on the importance of core public health systems and the global conditions that lead to disease emergence and pandemic spread. This is an opportunity for the global health community, particularly its funders, researchers, and practitioners, to better align with WHO and IPCC in their calls for action on climate and health and usher in a new age in global health practice. The climate is changing rapidly, time is short, and options are increasingly limited: strong action must be taken now.

The global health community of governments, particularly the G2O, and funders, particularly leaders including the NIH, the BMGF, and the Wellcome Trust, must seize the moment and take up the recommendations from WHO, the IPCC, and increasingly vocal members of the global health research and practice communities to prioritize equity, efficiency, and sustainability, 53 including vigorous action on climate change and infectious disease. To protect hard won gains, the global health community needs to recognize its shortcomings, broaden and expand its perspective, assume a proactive posture, and intensify its activity. Our vision is for a sustainable, proactive new age in global health, in which it expands its frame, leads by example, works with partners from other disciplines, invests in new skill development and interventions, and is resilient to extreme events, shocks, and large population movements.

A reorientation of global health practice requires input and engagement from all of its actors. Development and health agencies need to incorporate recommendations for changing priorities and practice. Funders-particularly the BMGF, which has a disproportionate effect on information flow and priority setting through its support of the GBD study-have an important role to play in framing the problem, promoting transdisciplinary approaches, and increasing transparency and accountability. Opportunities to expand current efforts to incorporate climate action abound. Assessments of action on the sustainable development goals (SDGs) and their health impacts, ${ }^{6970}$ for example, could easily expand to incorporate climate action. Both governments and funders have important roles in prioritizing decarbonization in global health programming, practice, and research, including efforts to green global health supply chains and reduce health sector carbon intensity. Practitioners have a role to play as well, by demanding that investment in transdisciplinary training and data integration become routine and creating pathways for career development in climate and health.

Health organizations including ministries and large

non-governmental actors should engage with scientists from various disciplines (such as climatology, ecology, social sciences, biology, modeling) to design and prioritize policy oriented research, including strengthening and evaluating adaptation of the health systems. This involves greening our own practice; investing in substantial, durable interdisciplinary activities and effective data sharing; breaking down informational and disciplinary silos; wrestling with complex issues beyond diagnostics and therapeutics; and supporting decisions that reduce health risks across multiple sectors. This will take substantial, sustained investment; development of new training pathways; support of new data streams; and commitment to working with stakeholders, including communities and policy makers.

Global health needs to think more holistically and act more comprehensively. We know what challenges climate change brings and how to respond. Now we need the will.

\section{Key recommendations}

- Prioritize decarbonization in the health sector and global health practice

- Increase funding for climate and health research and practice

- Encourage a transdisciplinary approach and support interdisciplinary activity

- Incorporate environmental information into public health practice and assessments

- Invest in decision support modeling tools and communication

- Build human capacity in data management, integrated surveillance, and leadership

Competing interests: We have read and understood BMJ policy on competing interests and declare the following: none.

This article is part of a series commissioned by The BMJ for the World Innovation Summit for Health (WISH) 2020. The BMJ peer reviewed, edited, and made the decisions to publish. The series, including open access fees, is funded by WISH.

Costello A, Abbas M, Allen A, etal. Managing the health effects of climate change: Lancet and University College London Institute for Global Health Commission. Lancet 2009;373:1693-733. doi: 10.1016/S0140-6736(09)60935-1 pmid: 19447250 
2 Wu X, Lu Y, Zhou S, Chen L, Xu B. Impact of climate change on human infectious diseases: Empirical evidence and human adaptation. Environ Int 2016;86:14-23. doi: 10.1016/.jenvint.2015.09.007 pmid: 26479830

3 Eckelman MJ, Sherman JD. Estimated global disease burden from US health care sector greenhouse gas emissions. Am J Public Health 2018:108(S2):S120-2.

doi: 10.2105/AJPH.2017.303846 pmid: 29072942

4 McMichael AJ, Friel S, Nyong A, Corvalan C. Global environmental change and health: impacts, inequalities, and the health sector. BMJ 2008;336:191-4 doi: 10.1136/bmi.39392.473727.AD pmid: 18219041

5 Intergovernmental Panel on Climate Change. Climate change 2007-impacts, adaptation and vulnerability: working group II contribution to the fourth assessment report of the IPCC. 2007. https://www.ipcc.ch/site/assets/uploads/2018/03/ar4-wg2-intro.pdf

6 Intergovernmental Panel on Climate Change. Managing the risks of extreme events and disasters to advance climate change adaptation: special report of the intergovernmental panel on climate change. 2012. https://www.ipcc.ch/report/managing-the-risks-of-extreme-events-and-disastersto-advance-climate-change-adaptation/

7 Intergovernmental Panel on Climate Change. Climate change 2014: Impacts, adaptation, and vulnerability. Contribution of working group II to the fifth assessment report of the intergovernmental panel on climate change. 2014. https:/www.ipcc.ch/report/ar5/wg2/

8 Ebi KL, Semenza JC, Rocklöv J. Current medical research funding and frameworks are insufficient to address the health risks of global environmental change. Environ Health 2016;15:108. doi: 10.1186/s12940-016-0183-3 pmid: 27835959

9 Papworth A, Maslin M, Randalls S. Is climate change the greatest threat to global health? Geogr J2015;181:413-22doi: 10.1111/geoj.12127

10 Kovats S, Haines A. The potential health impacts of climate change: an overview. Med War 1995;11:168-78. doi: 10.1080/07488009508409236 pmid: 8559115

11 Githeko AK, Lindsay SW, Confalonieri UE, Patz JA. Climate change and vector-borne diseases: a regional analysis. Bull World Health Organ 2000;78:1136-47.pmid: 11019462

12 Ogden NH, Lindsay LR. Effects of climate and climate change on vectors and vector-borne diseases: ticks are different. Trends Parasitol 2016;32:646-56. doi: 10.1016/.jpt.2016.04.015 pmid: 27260548

13 Parham PE, Waldock J, Christophides GK, etal. Climate, environmental and socio-economic change: weighing up the balance in vector-borne disease transmission. Philos Trans $R$ Soc Lond B Biol Sci 2015;370:20130551. doi: 10.1098/rstb.2013.0551 pmid: 25688012

14 Semenza JC, Lindgren E, Balkanyi L, etal. Determinants and drivers of infectious disease threat events in Europe. Emerg Infect Dis 2016;22:581-9. doi: 10.3201/eid2204.151073 pmid: 26982104

$15 \mathrm{Kyu} \mathrm{HH}$, Abate D, Abate KH, etalGBD 2017 DALYs and HALE Collaborators. Global, regional, and national disability-adjusted life-years (DALYS) for 359 diseases and injuries and healthy life expectancy (HALE) for 195 countries and territories, 1990-2017: a systematic analysis for the Global Burden of Disease Study 2017. Lancet 2018;392:1859-922. doi: 10.1016/S0140-6736(18)32335-3 pmid: 30415748

16 Caminade C, McIntyre KM, Jones AE. Impact of recent and future climate change on vector-borne diseases. Ann N Y Acad Sci 2019;1436:157-73. doi: 10.1111/nyas.13950 pmid: 30120891

17 Liang L, Gong P. Climate change and human infectious diseases: A synthesis of research findings from global and spatio-temporal perspectives. Environ Int 2017;103:99-108. doi: 10.1016/j.envint.2017.03.011 pmid: 28342661

18 Lowe R, Gasparrini A, Van Meerbeeck CJ, etal. Nonlinear and delayed impacts of climate on dengue risk in Barbados: A modelling study. PLoS Med 2018;15:e1002613. doi: 10.1371/journal.pmed.1002613 pmid: 30016319

19 Jones KE, Patel NG, Levy MA, etal. Global trends in emerging infectious diseases. Nature 2008:451:990-3. doi: 10.1038/nature06536 pmid: 18288193

20 Plowright RK, Parrish CR, McCallum H, etal. Pathways to zoonotic spillover. Nat Rev Microbiol 2017;15:502-10. doi: 10.1038/nrmicro.2017.45 pmid: 28555073

21 Fornace KM, Brock PM, Abidin TR, etal. Environmental risk factors and exposure to the zoonotic malaria parasite Plasmodium knowlesi across northern Sabah, Malaysia: a population-based cross-sectional survey. Lancet Planet Health 2019;3:e179-86. doi: 10.1016/S2542-5196(19)30045-2 pmid: 31029229

22 Waitz Y, Paz S, Meir D, Malkinson D. Temperature effects on the activity of vectors for Leishmania tropica along rocky habitat gradients in the Eastern Mediterranean. J Vector Ecol 2018;43:205-14. doi: 10.1111/jvec.12304 pmid: 30408284

23 Waitz Y, Paz S, Meir D, Malkinson D. Effects of land use type, spatial patterns and host presence on Leishmania tropica vectors activity. Parasit Vectors 2019;12:320. doi: 10.1186/s13071-019-3562-0 pmid: 31238938

24 El Zowalaty ME, Järhult JD. From SARS to COVID-19: a previously unknown SARS-CoV-2 virus of pandemic potential infecting humans - call for a one health approach. One Health 2020:100124. doi: 10.1016/.onehlt.2020.100124 pmid: 32195311

25 Ebi KL, Ogden NH, Semenza JC, Woodward A. Detecting and attributing health burdens to climate change. Environ Health Perspect 2017;125:085004. doi: 10.1289/EHP1509 pmid: 28796635

26 Gubler DJ. Dengue, urbanization and globalization: the unholy trinity of the 21st century. Trop Med Health 2011;39(Suppl):3-11. doi: 10.2149/tmh.2011-S05 pmid: 22500131

27 Rocklöv J, Tozan Y. Climate change and the rising infectiousness of dengue. Emerg Top Life Sci 2019;3:133-42doi: 10.1042/ETLS20180123

28 Liu Y, Lillepold K, Semenza JC, Tozan Y, Quam MBM, Rocklöv J. Reviewing estimates of the basic reproduction number for dengue, Zika and chikungunya across global climate zones. Environ Res 2020;182:109114. doi: 10.1016/j.envres.2020.109114 pmid: 31927301
29 Ogden NH. Climate change and vector-borne diseases of public health significance. FEMS Microbiol Lett 2017;364 . doi: 10.1093/femsle/fnx186 pmid: 28957457

30 Medlock JM, Leach SA. Effect of climate change on vector-borne disease risk in the UK. Lancet Infect Dis 2015;15:721-30. doi: 10.1016/S1473-3099(15)70091-5 pmid: 25808458

31 Siraj AS, Santos-Vega M, Bouma MJ, Yadeta D, Ruiz Carrascal D, Pascual M. Altitudinal changes in malaria incidence in highlands of Ethiopia and Colombia. Science 2014;343:1154-8. doi: 10.1126/science.1244325 pmid: 24604201

32 Ogden NH, Radojević M, Wu X, Durvuri VR, Leighton PA, Wu J. Estimated effects of projected climate change on the basic reproductive number of the Lyme disease vector Ixodes scapularis. Environ Health Perspect 2014;122:631-8. doi: 10.1289/ehp.1307799 pmid: 24627295

33 Robert MA, Tinunin DT, Benitez EM, etal. Arbovirus emergence in the temperate city of Córdoba, Argentina, 2009-2018. Sci Data 2019;6:276. doi: 10.1038/s41597-019-0295-z pmid: 31754110

34 Paz S. Climate change impacts on West Nile virus transmission in a global context. Philos Trans R Soc Lond B Biol Sci 2015;370:20130561. . doi: 10.1098/rstb.2013.0561 pmid: 25688020

35 Lillepold K, Rocklöv J, Liu-Helmersson J, Sewe M, Semenza JC. More arboviral disease outbreaks in continental Europe due to the warming climate?] Travel Med 2019;26:taz017. doi: 10.1093/itm/taz017 pmid: 30850834

36 Rocklöv J, Tozan Y, Ramadona A, etal. Using big data to monitor the introduction and spread of Chikungunya, Europe, 2017. Emerg Infect Dis 2019;25:1041-9. doi: 10.3201/eid2506.180138 pmid: 31107221

37 Caminade C, Turner J, Metelmann S, etal. Global risk model for vector-borne transmission of Zika virus reveals the role of El Niño 2015. Proc Natl Acad Sci U S A 2017;114:119-24. doi: 10.1073/pnas.1614303114 pmid: 27994145

38 Kraemer MUG, Reiner RC, JrBrady OJ, etal. Past and future spread of the arbovirus vectors Aedes aegypti and Aedes albopictus. Nat Microbiol 2019;4:854-63. doi: 10.1038/s41564-019-0376-y pmid: 30833735

39 Semenza JC, Tran A, Espinosa L, Sudre B, Domanovic D, Paz S. Climate change projections of West Nile virus infections in Europe: implications for blood safety practices. Environ Health 2016;15(Suppl 1):28. doi: 10.1186/s12940-016-0105-4 pmid: 26961903

40 Trisos $\mathrm{CH}$, Merow C, Pigot AL. The projected timing of abrupt ecological disruption from climate change. Nature 2020;580:496-501. doi: 10.1038/541586-020-2189-9 pmid: 32322063

41 Bálint M, Domisch S, Engelhardt CHM, etal. Cryptic biodiversity loss linked to global climate change. Nat Clim Chang 2011;1:313-8doi: 10.1038/nclimate1191 .

42 Pires APF, Srivastava DS, Marino NAC, MacDonald AAM, Figueiredo-Barros MP, Farjalla VF. Interactive effects of climate change and biodiversity loss on ecosystem functioning. Ecology 2018;99:1203-13. doi: 10.1002/ecy.2202 pmid: 29714828

43 Aguirre AA. Changing patterns of emerging zoonotic diseases in wildlife, domestic animals, and humans linked to biodiversity loss and globalization. ILAR J 2017;58:315-8. doi: 10.1093/ilar/ilx035 pmid: 29253148

44 Cotar Al, Falcuta E, Prioteasa LF, Dinu S, Ceianu CS, Paz S. Transmission dynamics of the West Nile virus in mosquito vector populations under the influence of weather factors in the Danube Delta, Romania. Ecohealth 2016;13:796-807. doi: 10.1007/s10393-016-1176-y pmid: 2770931

45 Leigh J, Moon S, Garcia E, et al. Is global capacity to manage outbreaks improving? Graduate Institute of International and Development Studies. 2018. https://repository.graduateinstitute.ch/record/296637/files/wp_0017_V3.pdf

46 Fanzo J, Davis C, McLaren R, etal. The effect of climate change across food systems: Implications for nutrition outcomes. Glob Food Secur 2018;18:12-9doi: 10.1016/j.gfs.2018.06.001 .

47 Brzoska M, Fröhlich C. Climate change, migration and violent conflict: vulnerabilities, pathways and adaptation strategies. Migr Dev 2016;5:190-210doi: 10.1080/21632324.2015.1022973.

48 Pichler PP, Jaccard IS, Weisz U, Weisz H. International comparison of health care carbon footprints. Environ Res Lett 2019;14:064004doi: 10.1088/1748-9326/ab19e1.

49 Intergovernmental Panel on Climate Change. An IPCC Special Report on the impacts of global warming of $1.5^{\circ} \mathrm{C}$ above pre-industrial levels and related global greenhouse gas emission pathways, in the context of strengthening the global response to the threat of climate change, sustainable development, and efforts to eradicate. 2018. https://www.ipcc.ch/sr15/

50 Sustainable Development Unit, UK National Health Service. 2009 NHS England Carbon Emissions: Carbon Footprinting Report (Sustainable Development Commission) (https://research-repository.st-andrews.ac.uk/handle/10023/2377)

51 Watts N, Adger WN, Ayeb-Karlsson S, etal. The Lancet Countdown: tracking progress on health and climate change. Lancet 2017:389:1151-64. doi: 10.1016/S0140-6736(16)32124-9 pmid: 27856085

52 Castro MC, Baeza A, Codeço CT, etal. Development, environmental degradation, and disease spread in the Brazilian Amazon. PLoS Biol 2019;17:e3000526. doi: 10.1371/journal.pbio.3000526 pmid: 31730640

53 Dieleman JL, Cowling K, Agyepong IA, etal. The G20 and development assistance for health: historical trends and crucial questions to inform a new era. Lancet 2019;394:173-83. doi: 10.1016/S0140-6736(19)31333-9 pmid: 31257126

54 Lowe R, Barcellos C, Coelho CAS, etal. Dengue outlook for the World Cup in Brazil: an early warning model framework driven by real-time seasonal climate forecasts. Lancet Infect Dis 2014;14:619-26. doi: 10.1016/S1473-3099(14)70781-9 pmid: 24841859

55 Nissan $\mathrm{H}$, Goddard L, de Perez EC, etal. On the use and misuse of climate change projections in international development. Wiley Interdiscip Rev Clim Change2019;10:e579doi: 10.1002/wcc.579 
56 Le Quéré C, Jackson RB, Jones MW, etal. Temporary reduction in daily global CO 2 emissions during the COVID-19 forced confinement. Nat Clim Chang 2020:1-7.

57 Lahcen B, Brusselaers J, Vrancken K, etal. Green recovery policies for the covid-19 crisis: modelling the impact on the economy and greenhouse gas emissions. Environ Resour Econ 2020:1-20.

58 Patz JA, Gibbs HK, Foley JA, Rogers JV, Smith KR. Climate change and global health: quantifying a growing ethical crisis. EcoHealth 2007;4:397-405doi: 10.1007/s10393-007-0141-1.

59 Whitmee S, Haines A, Beyrer C, etal. Safeguarding human health in the Anthropocene epoch: report of The Rockefeller Foundation-Lancet Commission on planetary health. Lancet 2015;386:1973-2028. doi: 10.1016/S0140-6736(15)60901-1 pmid: 26188744

60 Butler CD. Planetary epidemiology: towards first principles. Curr Environ Health Rep 2018;5:418-29. doi: 10.1007/s40572-018-0220-1 pmid: 30317533

61 Marmot M. Social determinants of health inequalities. Lancet 2005;365:1099-104. doi: 10.1016/S0140-6736(05)71146-6 pmid: 15781105

62 Schulz A, Northridge ME. Social determinants of health: implications for environmental health promotion. Health Educ Behav2004;31:455-71. doi: 10.1177/1090198104265598 pmid: 15296629

63 Rivers C, Chretien J-P, Riley S, etal. Using "outbreak science" to strengthen the use of models during epidemics. Nat Commun2019;10:3102. doi: 10.1038/s41467-019-11067-2 pmid: 31308372

64 Hewitson B, Waagsaether K, Wohland J, etal. Climate information websites: an evolving landscape. Wiley Interdiscip Rev Clim Change 2017;8:51doi: 10.1002/wcc.470 .

65 Lowe R, Stewart-Ibarra AM, Petrova D, etal. Climate services for health: predicting the evolution of the 2016 dengue season in Machala, Ecuador. Lancet Planet Health 2017;1:e142-51. doi: 10.1016/S2542-5196(17)30064-5 pmid: 29851600

66 Patz JA, Epstein PR, Burke TA, Balbus JM. Global climate change and emerging infectious diseases. JAMA 1996;275:217-23. doi: 10.1001/jama.1996.03530270057032 pmid: 8604175

67 Stewart-Ibarra AM, Romero M, Hinds AQJ, etal. Co-developing climate services for public health: Stakeholder needs and perceptions for the prevention and control of Aedes-transmitted diseases in the Caribbean. PLoS Negl Trop Dis 2019;13:e0007772. doi: 10.1371/journal.pntd.0007772 pmid: 31658267

68 Koplan JP, Bond TC, Merson MH, etalConsortium of Universities for Global Health Executive Board. Towards a common definition of global health. Lancet 2009;373:1993-5. doi: 10.1016/S0140-6736(09)60332-9 pmid: 19493564

69 Lim SS, Allen K, Bhutta ZA, etalGBD 2015 SDG Collaborators. Measuring the health-related Sustainable Development Goals in 188 countries: a baseline analysis from the Global Burden of Disease Study 2015. Lancet 2016;388:1813-50. doi: 10.1016/S0140-6736(16)31467-2 pmid: 27665228

70 Fullman N, Barber RM, Abajobir AA, etalGBD 2016 SDG Collaborators. Measuring progress and projecting attainment on the basis of past trends of the health-related Sustainable Development Goals in 188 countries: an analysis from the Global Burden of Disease Study 2016. Lancet 2017;390:1423-59. doi: 10.1016/S0140-6736(17)32336-X pmid: 28916366

This is an Open Access article distributed in accordance with the Creative Commons Attribution Non Commercial (CC BY-NC 4.0) license, which permits others to distribute, remix, adapt, build upon this work non-commercially, and license their derivative works on different terms, provided the original work is properly cited and the use is non-commercial. See: http://creativecommons.org/licenses/by$n c / 4.0 \%$. 